\title{
SPECIES DISCRIMINATION OF MANGROVES USING DERIVATIVE SPECTRAL ANALYSIS
}

\author{
K. Arun Prasad ${ }^{\text {a, } * \text { L. Gnanappazham }}{ }^{\mathrm{a}}$ \\ ${ }^{a}$ Department of Earth and Space Sciences, Indian Institute of Space Science and Technology, Thiruvananthapuram, Kerala, India \\ (arunprasadk.11, gnanam)@iist.ac.in
}

Commission VIII, WG VI/4

KEY WORDS: Mangroves, Bhitarkanika, Spectral signature, Derivative analysis, Species discrimination, Statistical analysis

\begin{abstract}
:
Mangroves are salt tolerant trees or shrubs commonly seen in mudflats of intertidal regions of tropical and subtropical coastlines. Recent advances in field spectroscopic techniques enabled the species level discrimination among closely related vegetation types. In this study we have analysed the laboratory spectroscopy data collected from eight species of Rhizophoraceaea family of mangroves. The spectral data ranges between the wavelength of $350 \mathrm{~nm}$ and $2500 \mathrm{~nm}$ at a very narrow bandwidth of $1 \mathrm{~nm}$. Preprocessing techniques including smoothing were done on the spectra to remove the noise before compiling it to a spectral library. Derivative analysis of the spectra was done and its corresponding first and second derivatives were obtained. Statistical analysis such as parametric and non-parametric tests were implemented on the original processed spectra as well as their respective first and second order derivatives for the identification of significant bands for species discrimination. Results have shown that red edge region $(680 \mathrm{~nm}-720 \mathrm{~nm})$ and water vapour absorption region around $1150 \mathrm{~nm}$ and $1400 \mathrm{~nm}$ are optimal as they were consistent in discriminating species in reflectance spectra as well as in its first and second derivative spectra. $C$. decandra species is found to be discriminable from other species while reflectance and its derivative spectra were used. Non-parametric statistical analysis gave better results than that of parametric statistical analysis especially in SWIR 2 spectral region $(1831 \mathrm{~nm}-2500 \mathrm{~nm})$.
\end{abstract}

\section{INTRODUCTION}

Mangroves represent vegetation ecosystem commonly thriving in silt or clay soil in the intertidal zone of tropical and subtropical coastlines (Tomlinson, 1994). In total, about 110 known plant species were identified as mangroves. Out of them, 54 species belonging to 20 genera of 16 families were categorised as true mangrove species living in the core zone (Kuenzer et al., 2011) and remaining species were represented as associated species as they found associated with mangroves and often occur in transition zone between mangrove ecosystem and terrestrial ecosystems. Mangrove community is vulnerable to extreme environmental conditions such as high temperature, high salinity, extreme tides and strong wind conditions but are well adapted and thrive in those conditions. Mangrove community forms perpetual natural resource with rich floral and faunal diversity making it as a complex ecosystem to evaluate. Mangroves form a natural barrier along the coast and act as a shield for coastal community against natural calamities such as cyclones, storm surges and tsunamis (Alongi, 2008; Kathiresan and Rajendran, 2005). Rhizophoraceae mangroves are found abundant along Indian coastlines which makes it as a important community to evaluate. Tomlinson (1994) categorised members of Rhizophoraceae family into four genera namely Bruguiera, Ceriops, Kandelia and Rhizophora with a total 18 mangrove species. In earlier days, the regular monitoring and conservation activities associated with mangroves were difficult due to the inhospitable condition prevailing there. Remote sensing technology helped the planners to make decisions regarding their monitoring, conservation and restoration activities of mangrove ecosystems in India (Ramasubramanian et al., 2006; Selvam et al., 2003). Kuenzer et al. (2011) has reviewed the studies done using remote sensing aided mangrove vegetation community mapping throughout the world. Space Application Centre (SAC) has made community level map for mangrove ecosystems in India using multispectral remote sensing data from LISS III sensor of IRS 1C and IRS 1D (Ajai et al., 2012; Nayak and Bahuguna, 2001). Over the past few decades, innovations in remote sensing technology such as hyperspectral remote sensing has made a break through by its continuous spectral data which are helpful in discriminating features having similar spectra in multispectral domain. Spectroradiometer provides pure spectral reflectance value of feature of interest placed in its field of view from its in-situ measurement. Spectral library generation for various agricultural and wetland species were successfully attempted and results indicated the existence of unique spectral signatures for particular species during its unique phase of their growth (Rao et al., 2007; Zomer et al., 2009). Spectral discrimination had been studied by utilizing field and lab reflectance data of various vegetation types such as agricultural crops (Song et al., 2011), Mediterranean species (Manevski et al., 2011) and also coastal vegetation including mangroves (Manjunath et al., 2013; Panigrahy et al., 2012; Schmidt and Skidmore, 2003; Vaiphasa et al., 2005). Apart from that both airborne and satellite based hyperspectral image data were used to discriminate mangrove species at finer levels (Held et al., 2003; Hirano et al., 2003; Koedsin and Vaiphasa, 2013; Kumar et al., 2013). Some studies were conducted based on the derivative spectral analysis of hyperspectral data such as conifer species identification using in-situ spectral data of range $350 \mathrm{~nm}$ to $1050 \mathrm{~nm}$ (Gong et al., 1997), optimal band selection for wetland species identification using second derivative spectra (Becker et al., 2005) and identifying plant stress caused

\footnotetext{
* Corresponding author.
} 
due to gas leaks using derivative spectral ratios in red edge region (Smith et al., 2004).

In this paper we investigated the spectral discrimination among eight mangrove species of Rhizophoraceae family using their laboratory spectral reflectance data by implementing statistical tools such as parametric and non-parametric tests. Derivative spectral analysis was conducted to obtain their first and second derivatives for the spectral discrimination analysis and to identify the optimal wavelengths which are very consistent in spectral discrimination.

\section{MATERIALS AND METHODOLOGY}

\subsection{Study Area}

Bhitarkanika National Park is situated in north-eastern part of the state, Odisha in Indian east coast. It is located in the combined estuarine region of rivers Brahmani, Baitrani and Dhamra and has rich alluvial deposits with gently sloping topography. The total area of Bhitarkanika wildlife sanctuary is 672 sq. km., of which core area of $145 \mathrm{sq}$. km. covered by mangrove forest was declared as National park in 1998. In the year 2002, Bhitarkanika mangrove ecosystem was declared as 'Ramsar' site - A wetland of International importance by Ramsar Convention of Wetlands. The study area lies between $20^{\circ} 38^{\prime} 19^{\prime \prime} \mathrm{N}-20^{\circ} 47^{\prime} 27^{\prime \prime} \mathrm{N}$ latitudes and 86 $46^{\prime} 26^{\prime \prime} \mathrm{E}$ $87^{\circ} 05^{\prime} 48^{\prime}$ ' E longitudes. This area experiences semi diurnal high and low tides twice a day with the tidal amplitude ranges between $2 \mathrm{~m}-3.5 \mathrm{~m}$ in upstream and $3.5 \mathrm{~m}-6 \mathrm{~m}$ near to river mouths (Ravishankar et al., 2004). In Bhitarkanika, 76 mangrove species were identified. In which 30 are true species and 46 are associated species. Major species found here are Avicennia marina, Avicennia officinalis, Ceriops decandra, Excoecaria agallocha, Heritiera fomes, Kandelia candel, Sonneratia apetala, Sonneratia caseolaris, Xylocarpus granatum and Xylocarpus moluccensis.

\subsection{Laboratory spectral data collection and pre-processing}

Laboratory spectral data were collected from eight mangrove species of Rhizophoracaeae such as Bruguiera gymnorrhiza (BG), Bruguiera parviflora (BP), Bruguiera sexangula (BS), Ceriops decandra (CD), Ceriops tagal (CT), Kandelia candel (KC), Rhizophora apiculata (RA) and Rhizophora mucronata (RM) which are prominent in Bhitarkanika National Park were chosen for this analysis. Spectral data were collected from twenty piles of freshly picked leaves of each of the eight species using Analytical Spectral Device (ASD) Fieldspec ${ }^{\circledR} 3$ spectroradiometer in a dark room environment. The sampling interval in which Fieldspec ${ }^{\circledR} 3$ records reflectance are $1.4 \mathrm{~nm}$ in the wavelength range between $350 \mathrm{~nm}$ and $1000 \mathrm{~nm}$ and of 3 $\mathrm{nm}$ in the wavelength range between $1001 \mathrm{~nm}$ and $2500 \mathrm{~nm}$. About 150 spectra were recorded for each species. Quartztungsten filament halogen lamp which gives consistent illumination in the range of $400 \mathrm{~nm}$ to $2500 \mathrm{~nm}$ was selected as the artificial source of light.

The collected spectra were subjected to pre-processing techniques such as a) splice correction at $1000 \mathrm{~nm}$ and 1830 $\mathrm{nm}, \mathrm{b})$ removal of non-illuminated bands between $350 \mathrm{~nm}$ and $400 \mathrm{~nm}$ and c) smoothing using Savitzky- Golay filter (polynomial order 2 and filter size 15). Then the processed spectra were compiled and spectral library was generated (Figure 1).

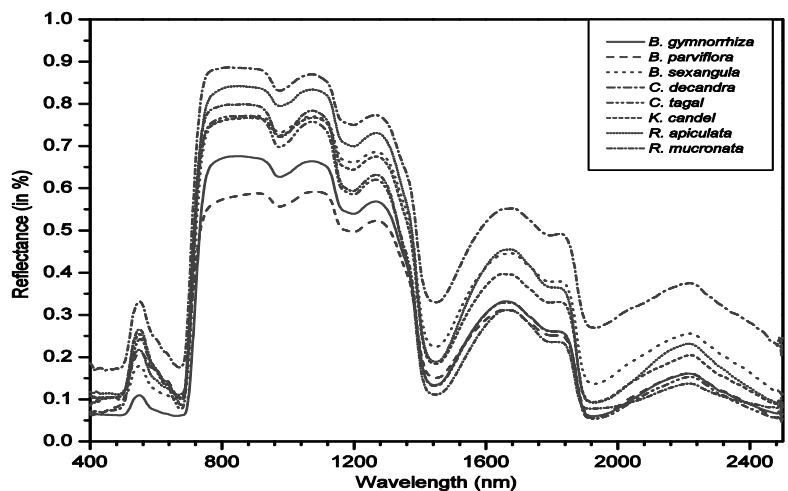

Figure 1. Laboratory spectra of Rhizophoraceae mangroves

\subsection{Derivative spectral analysis}

Spectral derivative analysis was done by dividing the difference between successive spectral values by its wavelength interval (bandwidth). Finite approximation method could be used to estimate derivatives based on the spectral resolution of the data (i.e., bandwidth) $\Delta \lambda$ (Tsai and Philpot, 1998). The formula used to estimate the first derivative is

$\left.\frac{d s}{d \lambda}\right|_{i} \approx \frac{s\left(\lambda_{i}\right)-s\left(\lambda_{j}\right)}{\Delta \lambda}$,

where, $\Delta \lambda$ is the band width which is given as $\Delta \lambda=\lambda_{j}-\lambda_{i}$ and also $\lambda_{j}>\lambda_{i}$. Here $\Delta \lambda$ (1nm) is constant throughout the spectrum.

The second derivative was calculated from the first derivative and it could be expressed as

$\left.\frac{d^{2} y}{d x^{2}}\right|_{j}=\left.\frac{d}{d \lambda}\left(\frac{d s}{d \lambda}\right)\right|_{j} \approx \frac{s\left(\lambda_{i}\right)-2 s\left(\lambda_{j}\right)+s\left(\lambda_{k}\right)}{(\Delta \lambda)^{2}}$

where, $\Delta \lambda=\lambda_{k}-\lambda_{j}=\lambda_{j}-\lambda_{i}$ and $\lambda_{k}>\lambda_{j}>\lambda_{i}$.

The spectral library was compiled from first and second order derivatives obtained from spectra of eight species. An example of these three spectra of $R$. apiculata is given in Figure 2.

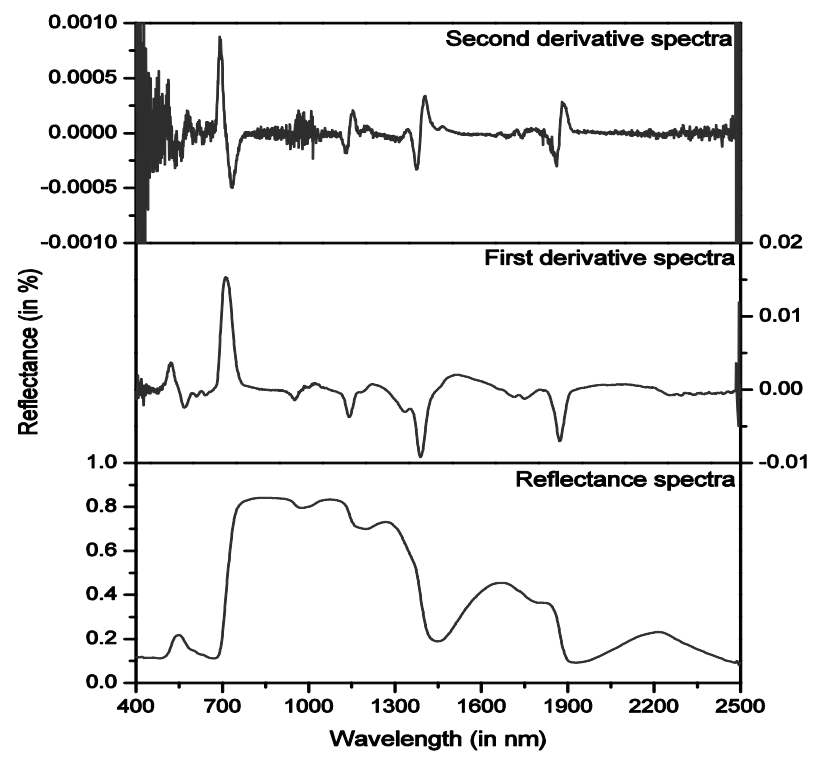

Figure 2. Reflectance and its respective derivative spectra of mangrove species Rhizophora apiculata 


\subsection{Statistical analysis for the identification of spectrally discriminable bands}

In the present study we used both parametric and nonparametric statistical analysis to identify bands having separability. For parametric statistical analysis, One way Analysis of Variance (ANOVA) test was chosen by assuming the null hypothesis

$\mathrm{H}_{\mathrm{o}}: \mu_{1}=\mu_{2}=\ldots \ldots \ldots . . .=\mu_{8}$

against the alternative hypothesis,

$\mathrm{H}_{\mathrm{a}}: \mu_{1} \neq \mu_{2} \neq \ldots \ldots \ldots \neq \ldots \mu_{8}$.

Here $\mu$ represents the mean spectral reflectance. This test was performed along with pair-wise Bonfferoni post-hoc test (McHugh, 2011) at each wavelength for $95 \%$ and $99 \%$ confidence level. The homogeneity of variance was tested prior to the analysis as it is a prerequisite to perform one way ANOVA test.

For non-parametric statistical analysis, Kruskal Wallis test was selected by assuming the null hypothesis

$\mathrm{H}_{\mathrm{o}}: \eta_{1}=\eta_{2}=\ldots \ldots \ldots . .=\eta_{8}$

against the alternative hypothesis,

$\mathrm{H}_{\mathrm{a}}: \eta_{1} \neq \eta_{2} \neq \ldots \ldots \ldots \neq \eta_{8}$

at every wavelength location considered for $95 \%$ and $99 \%$ confidence interval. Here $\eta$ represents the median spectral reflectance. Kruskal-Wallis test is similar to One-way ANOVA test that can be performed on ordinal (ranked) data. MannWhitney U test compares median spectral reflectance of two species to find out the spectral difference between them (Sheskin, 2004) at each wavelength location. Parametric and non-parametric tests were implemented on total of 28 such possible pairs of species combinations.

\section{RESULTS AND DISCUSSION}

The wavelengths (bands) which are spectrally significant for each species pairs were identified using parametric and nonparametric test at $95 \%$ and $99 \%$ confidence level. The results of both tests at $99 \%$ confidence interval for reflectance spectra and its corresponding first and second derivative spectra (here after referred as "three cases") are given in Table 1.

\subsection{Identification of spectrally significant bands using parametric statistical analysis:}

The wavelength location of spectrally significant bands obtained from parametric one-way ANOVA paired with Bonfferoni post-hoc test for 28 species pairs in three cases were identified. Scatter plot representing the location of significant wavelengths and the frequency plot representing number of the spectrally significant pairs at each wavelength in three cases are given in Figure 3.

In reflectance spectra, there are 8 species pairs which are separable in every wavelength and they are BG vs BS, BG vs $\mathrm{CD}, \mathrm{BP}$ vs $\mathrm{CD}$, $\mathrm{BS}$ vs $\mathrm{CD}, \mathrm{CD}$ vs $\mathrm{CT}, \mathrm{CD}$ vs $\mathrm{KC}, \mathrm{CD}$ vs $\mathrm{RA}$ and $\mathrm{CD}$ vs RM. Thus in reflectance mode the species $C$. decandra was found to be consistently separable from all the other species. Apart from that other species pairs which are separable in more than 2000 bands are BG vs KC, BG vs RA, $\mathrm{BP}$ vs BS, BP vs RA, BS vs CT, CT vs KC and RA vs RM. The species pair with least separability was identified as BG vs BP which was separable only in 903 bands. In first derivative spectra, species pairs such as BP vs RM, BS vs RM and RA vs RM were identified as most separable species pairs with more than 1200 significant bands each. R.mucronata is found to be the spectrally significant species while first derivative spectra were used. BG vs CT, BG vs $\mathrm{KC}$ and $\mathrm{BS}$ vs $\mathrm{KC}$ were identified as least separable species pairs. While second derivative spectra was used, $B P$ vs $C D, B S$ vs $C D$ and $C D$ vs RA were found to be more separable species pairs with almost more than 400 significant bands each. $C$. decandra was spectrally significant when second derivative spectra were used. Least separable species pairs were $\mathrm{BG}$ vs $\mathrm{CT}, \mathrm{CT}$ vs $\mathrm{KC}$ and $\mathrm{CT}$ vs RM making $C$. tagal, the least separable species while second derivative spectra were used.

Table 1. Number of significant wavelengths derived from parametric and non-parametric statistical analysis for each species pair at $99 \%$ confidence level while reflectance and its corresponding derivative spectra were used. The results of parametric one way ANOVA is given in lower left half and nonparametric Mann-Whitney U test (shaded in gray colour) is given in upper right half of the table

\begin{tabular}{|c|c|c|c|c|c|c|c|c|}
\hline \multicolumn{9}{|c|}{ REFLECTANCE SPECTRA } \\
\hline & BG & BP & BS & CD & CT & $\mathrm{KC}$ & RA & RM \\
\hline BG & & 1191 & 2100 & 2100 & 2045 & 2021 & 2095 & 1648 \\
\hline BP & 903 & & 2089 & 2100 & 1938 & 1960 & 2074 & 1807 \\
\hline BS & 2100 & 2058 & & 2100 & 2084 & 1415 & 1937 & 1704 \\
\hline CD & 2100 & 2100 & 2100 & & 2100 & 2100 & 2100 & 2100 \\
\hline CT & 1383 & 1262 & 2048 & 2100 & & 2050 & 2081 & 1771 \\
\hline $\mathrm{KC}$ & 2015 & 1987 & 1360 & 2100 & 2038 & & 1477 & 1423 \\
\hline RA & 2056 & 2028 & 1695 & 2100 & 1994 & 1509 & & 2040 \\
\hline RM & 1782 & 1471 & 1724 & 2100 & 1164 & 1562 & 2003 & \\
\hline \multicolumn{9}{|c|}{ FIRST DERIVATIVE SPECTRA } \\
\hline & BG & BP & BS & CD & CT & KC & RA & RM \\
\hline BG & & 1297 & 1016 & 1196 & 1305 & 1143 & 805 & 1004 \\
\hline BP & 1029 & & 1020 & 1104 & 961 & 1335 & 1111 & 1179 \\
\hline BS & 906 & 925 & & 1194 & 1151 & 1311 & 1242 & 1328 \\
\hline CD & 999 & 1172 & 825 & & 1327 & 732 & 1051 & 1091 \\
\hline CT & 707 & 1040 & 1050 & 1053 & & 1160 & 863 & 1132 \\
\hline KC & 731 & 942 & 697 & 871 & 816 & & 1077 & 1199 \\
\hline $\mathbf{R A}$ & 893 & 1191 & 1107 & 1146 & 1123 & 967 & & 1495 \\
\hline RM & 1074 & 1210 & 1256 & 1089 & 812 & 1013 & 1371 & \\
\hline \multicolumn{9}{|c|}{ SECOND DERIVATIVE SPECTRA } \\
\hline & BG & BP & BS & CD & CT & KC & $\mathbf{R A}$ & $\mathbf{R M}$ \\
\hline BG & & 414 & 339 & 433 & 410 & 386 & 294 & 342 \\
\hline BP & 170 & & 400 & 418 & 354 & 418 & 275 & 352 \\
\hline BS & 202 & 278 & & 383 & 413 & 414 & 368 & 428 \\
\hline CD & 342 & 395 & 414 & & 420 & 292 & 353 & 325 \\
\hline CT & 111 & 167 & 241 & 299 & & 362 & 271 & 313 \\
\hline KC & 165 & 194 & 233 & 263 & 123 & & 357 & 339 \\
\hline $\mathbf{R A}$ & 167 & 260 & 269 & 407 & 183 & 190 & & 379 \\
\hline $\mathbf{R M}$ & 220 & 247 & 330 & 384 & 122 & 176 & 293 & \\
\hline
\end{tabular}



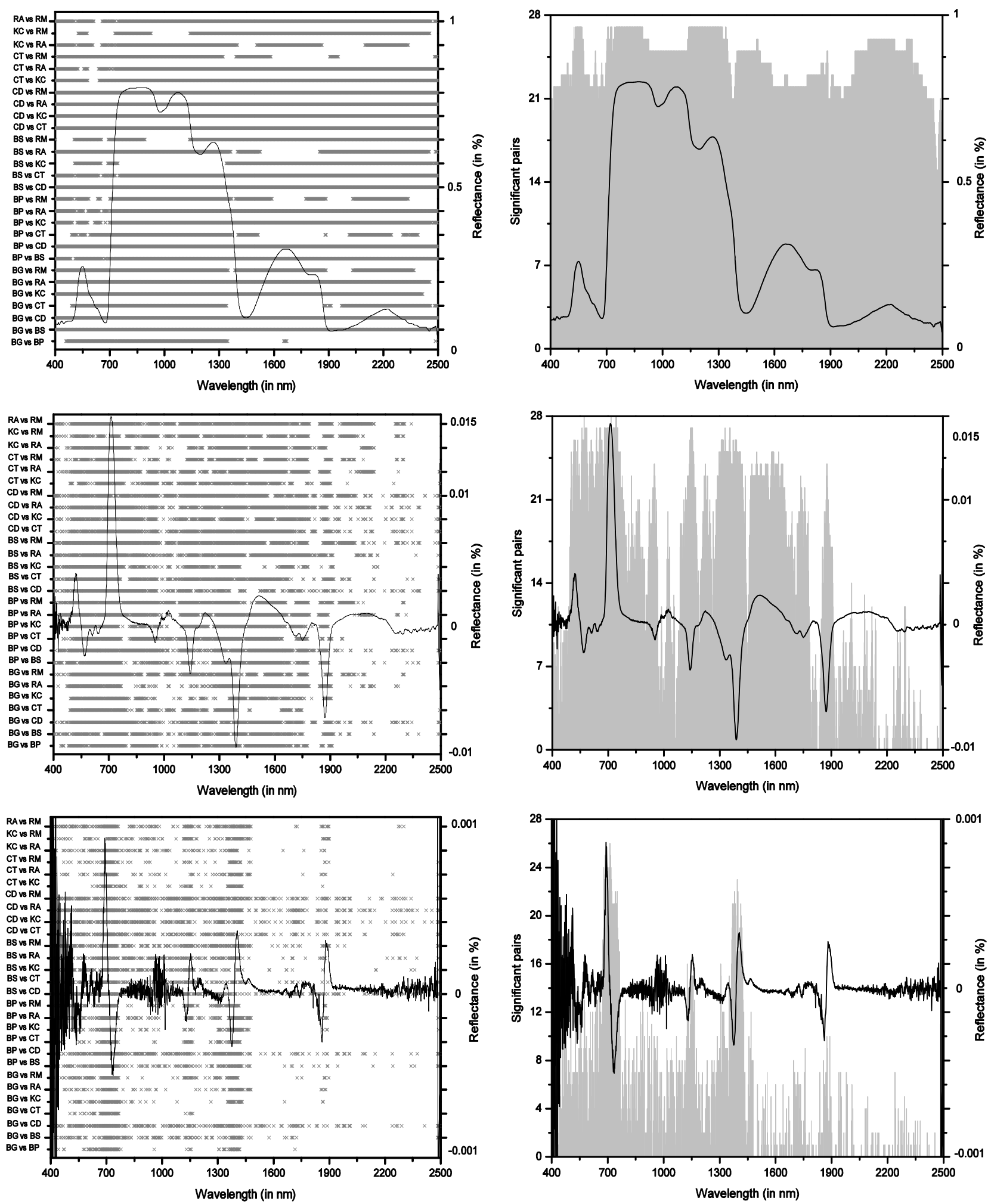

Figure 3. (i) Scatter plots (left side) and (ii) frequency plots (right side) depicting the location of spectrally significant (separable) bands and the number of statistically significant pairs at each wavelength location respectively obtained from parametric One way ANOVA paired with Bonfferoni test for 28 species pairs in three cases (Row wise - top to bottom: Reflectance spectra, First Derivative spectra and Second Derivative spectra) at $99 \%$ confidence interval. The average spectrum of $R$. apiculata species in each case is plotted in their respective scatter and frequency plots for easy interpretation. 

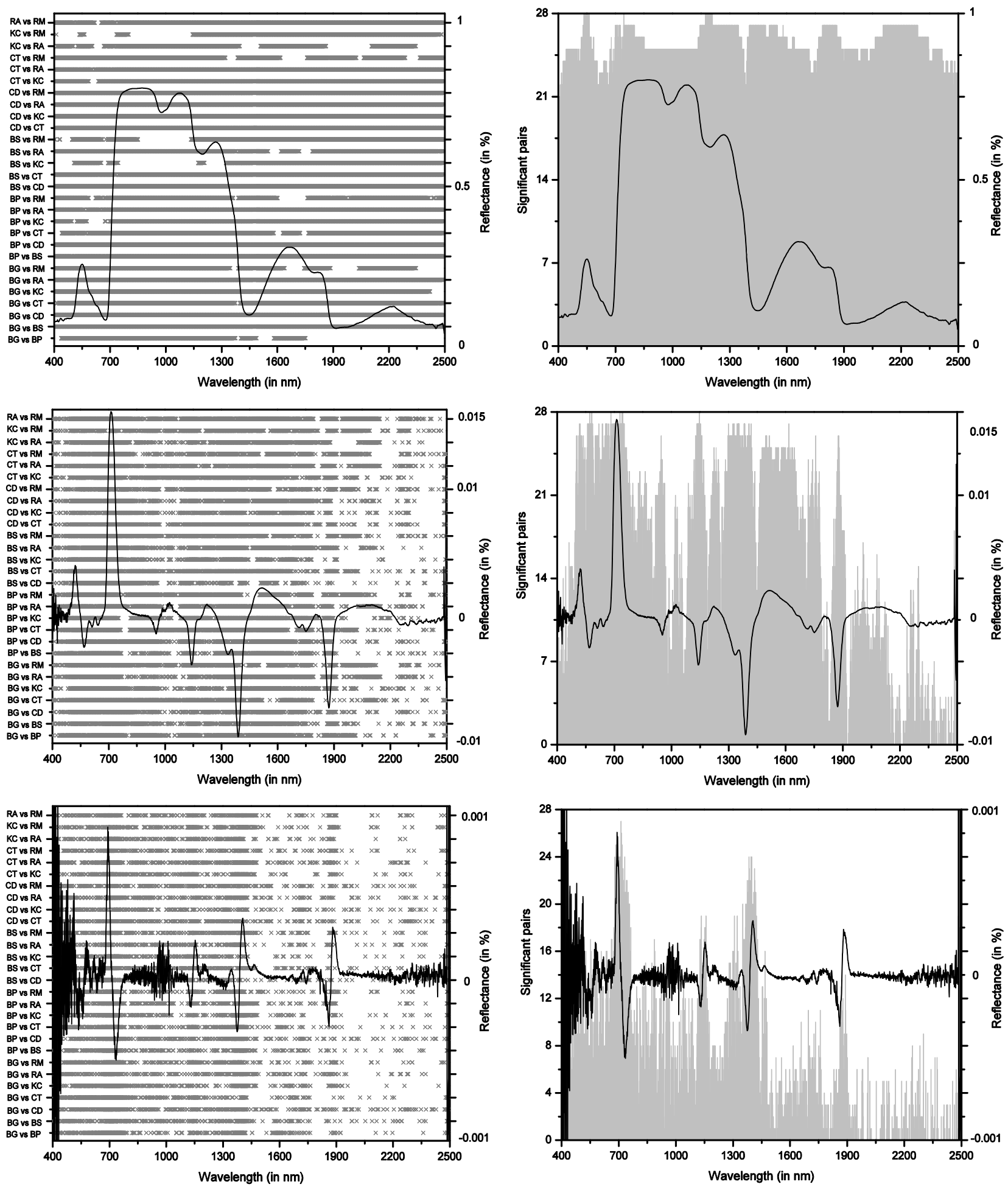

Figure 4. (i) Scatter plots (left side) and (ii) frequency plots (right side) depicting the location of spectrally significant (separable) bands and the number of statistically significant pairs at each wavelength location respectively obtained from non-parametric Kruskal Wallis test along with Mann Whitney U test for 28 species pairs in three cases (Row wise - top to bottom: Reflectance spectra, First Derivative spectra and Second Derivative spectra) at $99 \%$ confidence interval. The average spectrum of $R$. apiculata species in each case is plotted in their respective scatter and frequency plots for easy interpretation. 
Regarding the location of spectrally significant bands (wavelengths) in the spectral domain of $401 \mathrm{~nm}-2500 \mathrm{~nm}$, most of the species pairs are separable in green reflectance and red edge region. In first derivative spectra case, separability has become low in regions such as blue (400$500 \mathrm{~nm}$ ), absorption band around $1050 \mathrm{~nm}$, minor absorption band around $1800 \mathrm{~nm}$ and SWIR region between $1950 \mathrm{~nm}$ and $2500 \mathrm{~nm}$. In first derivative spectra, most of the species are separable in VNIR and SWIR 1 wavelength regions but not in SWIR 2 region. While considering the second derivative spectra case, higher separability was observed in red edge region $(680 \mathrm{~nm}-750 \mathrm{~nm})$ and also in water vapour absorption region around $1390 \mathrm{~nm}$. Considering the species pairs, most of the species pairs are separable in region between $400 \mathrm{~nm}$ and $1350 \mathrm{~nm}$ except BG vs BP, BG vs CT, BG vs KC, BG vs RA, BG vs RM, BP vs CT, BP vs KC, BP vs RA, CT vs KC, CT vs RA, CT vs RM and KC vs RM. The species $C$. decandra alone is separable from other species in most of the wavelengths in the region between $1451 \mathrm{~nm}$ and $2500 \mathrm{~nm}$.

\subsection{Identification of spectrally significant bands using non-parametric statistical analysis:}

The wavelength location of spectrally significant bands obtained from non-parametric Kruskal Wallis test along with Mann Whitney U-test for 28 species pairs using reflectance and corresponding first and second order derivative spectra were identified. The scatter plot representing the wavelength location of spectrally significant bands for 28 species pairs and frequency plot showing the number of spectrally discriminable pairs at each wavelength are given in Figure 4. The results reveal that spectral separability among species of Rhizophoraceae is found to be in higher order while analysed using non-parametric tests than parametric tests considered for this study. In reflectance spectra, eight species pairs which were completely discriminable at all wavelengths in parametric test were also completely discriminable while non-parametric test was applied. Apart from these eight species pairs species pairs such as BS vs BP, BS vs CT, BG vs RA, BP vs RA and CT vs RA were discriminable in most of the bands (>2074 bands). C. decandra and R. apiculata were identified as most discriminable species while reflectance spectra were used. Species pair with minimum separability was BP vs BG which was also similar to that of parametric test results. In first derivative spectra, most separability was obtained for $\mathrm{CD}$ vs $\mathrm{CT}, \mathrm{KC}$ vs $\mathrm{BP}, \mathrm{KC}$ vs BS, BS vs RM, RA vs RM. B. sexangula was found to be consistently separable from other species in first derivative spectra case. Minimum separability was observed in pairs such as BG vs RA, CD vs $\mathrm{KC}$ and $\mathrm{CT}$ vs RA. While in second derivative spectra, maximum separability was observed in species pairs such as $\mathrm{BG}$ vs $\mathrm{CD}, \mathrm{BP}$ vs $\mathrm{CD}$, BP vs $\mathrm{KC}$ and $\mathrm{BS}$ vs RM while minimum separability was observed in $\mathrm{KC}$ vs $\mathrm{CD}$, BP vs RA and CT vs RA.

While focusing on the distribution of spectrally significant bands of 28 species pairs in the wavelength domain considered, it is almost similar to parametric statistical test in reflectance spectra case with some exceptions like BG vs CT and BP vs CT. But in first derivative spectra the distribution of spectrally separable bands has improved in SWIR 2 region beyond $1900 \mathrm{~nm}$ in most cases when compared with parametric statistical test results. Also, separability in wavelengths regions around $450 \mathrm{~nm}$ and $1000 \mathrm{~nm}$ has improved in some cases such as BG vs CT, BG vs KC, BG vs $\mathrm{RA}, \mathrm{CT}$ vs $\mathrm{KC}, \mathrm{CT}$ vs RM and $\mathrm{KC}$ vs RA. In second derivative spectra case, there was much improvement observed in the spectrally separable bands between $1450 \mathrm{~nm}$ and $1950 \mathrm{~nm}$. Wavelengths beyond $1950 \mathrm{~nm}$ had also shown slight improvement in spectral separability in most cases.

When comparing the frequency plots of three cases in figure 3 and figure 4 , it is evident that frequency has certainly improved in non-parametric analysis when compared to that of parametric analysis. In reflectance spectra case, the frequency has increased in green reflectance $(\sim 550 \mathrm{~nm})$, Red edge $(680 \mathrm{~nm}-720 \mathrm{~nm})$, water absorption at $1150 \mathrm{~nm}$, SWIR bands $(1450 \mathrm{~nm}-2000 \mathrm{~nm})$ and in SWIR 2 region (beyond $2350 \mathrm{~nm}$ ). In first derivative spectra case, much improvement was evident in region around $1000 \mathrm{~nm}$ and bands beyond $1900 \mathrm{~nm}$. While in second derivative spectra, considerable improvement of frequency was observed beyond $1460 \mathrm{~nm}$.

While summarising the results, it is evident that there is significant difference between mangrove species of Rhizophoraceae in the spectral domain considered for this study. C. decandra has higher spectral separability from other species in reflectance and second derivative spectra cases. Red edge region $(680 \mathrm{~nm}-720 \mathrm{~nm})$ and water vapour absorption band around $1150 \mathrm{~nm}$ and $1400 \mathrm{~nm}$ are consistent in discriminating species in reflectance spectra as well its first and second derivative spectra. Non-parametric statistical analysis gave better results than parametric statistical analysis especially in SWIR 2 spectral region $(1831 \mathrm{~nm}-2500 \mathrm{~nm})$ of second derivative spectra. Results imply the dissimilarity in internal cell arrangement and thickness of leaves prevailing in different species of Rhizophoraceae.

\section{CONCLUSION}

In this paper, it is studied that how parametric and nonparametric statistical analysis could be used for discriminating species those belong to same family using laboratory spectral signatures. Separability using derivative spectral analysis was experimented and the results were useful to identify that red edge region and water vapour absorption region around $1450 \mathrm{~nm}$ were consistent in discriminating Rhizophoracea species. The spectral reflectance of leaves is characteristic of biochemical variables (i.e., cell pigments) such as chlorophyll, carotenoids etc. which is noticed in wavelength interval of $350 \mathrm{~nm}-700 \mathrm{~nm}$ (Das et al., 2002). The spectral variability in near infra-red and shortwave IR region indicates the difference in amount of scattering due to multiple refractions and reflections at the boundary between cellular walls and mesophyll cells among species, presence of nitrogen, protein, lignin and absorption due to water content present in leaves (Panigrahy et al., 2012; Tomlinson, 1994). The difference in thickness of 'achlorophyllous' tissues among Rhizophoraceae species also has a major impact on the difference in spectral reflectance in NIR and SWIR regions.

This method has successfully established the discrimination of mangrove species of Rhizophoraceae family which was reported "poorly discriminable" in earlier studies. Though overall separability among species was decreased when derivative spectra was used, the results were useful to identify most consistent bands for discriminating Rhizophoraceae species. The methodology followed would be used in discriminating the species for the selection of optimal bands while using hyperspectral satellite data to enhance the classification accuracy. 


\section{ACKNOWLEDGEMENT}

The authors are grateful to The Director, IIST for financial support to carry out the project. We are thankful to Dr. R. Ramasubramanian, Mr. B. M. Praveen Kumar and Mr. M. Yedukondalu of MSSRF, Kakinada, Andhra Pradesh, India for their support in field data collection. The authors are also thankful to Department of Forests, Government of Odisha for giving permission to carry out our field data collection.

\section{REFERENCES}

Ajai, Bahuguna, A., Chauhan, H.B., Sen Sarma, K., Bhattacharya, S., Ashutosh, S., Pandey, C.N., Thangaradjou, T., Gnanppazham, L., Selvam, V., Nayak, S.R., 2012. Mangrove Inventory of India at Community Level. National Academy Science Letters 36, pp. 67-77.

Alongi, D.M., 2008. Mangrove forests: Resilience, protection from tsunamis, and responses to global climate change. Estuarine, Coastal and Shelf Science 76, pp. 1-13.

Becker, B.L., Lusch, D.P., Qi, J., 2005. Identifying optimal spectral bands from in situ measurements of Great Lakes coastal wetlands using second-derivative analysis. Remote Sensing of Environment 97, pp. 238248.

Das, A.B., Parida, A., Basak, U.C., Das, P., 2002. Studies on pigments, proteins and photosynthetic rates in some mangroves and mangrove associates from Bhitarkanika, Orissa. Marine Biology 141, pp. 415422.

Gong, P., Pu, R., Yu, B., 1997. Conifer species recognition: An exploratory analysis of in situ hyperspectral data. Remote Sensing of Environment 62, pp. 189-200.

Held, A., Ticehurst, C., Lymburner, L., Williams, N., 2003. High resolution mapping of tropical mangrove ecosystems using hyperspectral and radar remote sensing. International Journal of Remote Sensing 24, pp. 2739-2759.

Hirano, A., Madden, M., Welch, R., 2003. Hyperspectral image data for mapping wetland vegetation. Wetlands 23, pp. 436-448.

Kathiresan, K., Rajendran, N., 2005. Coastal mangrove forests mitigated tsunami. Estuarine, Coastal and Shelf Science 65, pp. 601-606.

Koedsin, W., Vaiphasa, C., 2013. Discrimination of Tropical Mangroves at the Species Level with EO-1 Hyperion Data. Remote Sensing 5, pp. 3562-3582.

Kuenzer, C., Bluemel, A., Gebhardt, S., Quoc, T.V., Dech, S., 2011. Remote Sensing of Mangrove Ecosystems: A Review. Remote Sensing 3, pp. 878-928.

Kumar, T., Panigrahy, S., Kumar, P., Parihar, J.S., 2013. Classification of floristic composition of mangrove forests using hyperspectral data: case study of Bhitarkanika National Park, India. Journal of Coastal
Conservation Planning and Management 17, pp. 121132.

Manevski, K., Manakos, I., Petropoulos, G.P., Kalaitzidis, C., 2011. Discrimination of common Mediterranean plant species using field spectroradiometry. International Journal of Applied Earth Observation and Geoinformation 13, pp. 922-933.

Manjunath, K., Kumar, T., Kundu, N., Panigrahy, S., 2013. Discrimination of mangrove species and mudflat classes using in situ hyperspectral data: a case study of Indian Sundarbans. GIScience \& Remote Sensing 50, pp. 400-417.

McHugh, M.L., 2011. Multiple comparison analysis testing in ANOVA. Biochemia medica 21, pp. 203-209.

Nayak, S., Bahuguna, A., 2001. Application of remote sensing data to monitor mangroves and other coastal vegetation of India. Indian Journal of Marine Sciences 30, pp. 195-213.

Panigrahy, S., Kumar, T., Manjunath, K.R., 2012. Hyperspectral leaf signature as an added dimension for species discrimination: case study of four tropical mangroves. Wetlands Ecology and Management 20, pp. 101-110.

Ramasubramanian, R., Gnanappazham, L., Ravishankar, T., Navamuniyammal, M., 2006. Mangroves of Godavari - Analysis Through Remote Sensing Approach. Wetlands Ecology and Management 14, pp. 29-37.

Rao, N.R., Garg, P.K., Ghosh, S.K., 2007. Development of an agricultural crops spectral library and classification of crops at cultivator level using hyperspectral data. Precision Agriculture 8, pp. 173-185.

Ravishankar, T., Navamuniyammal, M., Gnanappazham, L., Nayak, S.S., Mahapatra, G.C., Selvam, V., 2004. Atlas of Mangrove Wetlands of India: Part 3 - Orissa. M. S. Swaminathan Research Foundation.

Schmidt, K.S., Skidmore, a. K., 2003. Spectral discrimination of vegetation types in a coastal wetland. Remote Sensing of Environment 85, pp. 92-108.

Selvam, V., Ravichandran, K.K., Gnanappazham, L., Navamuniyammal, M., 2003. Assessment of community-based restoration of Pichavaram mangrove wetland using remote sensing data. Current science 85 , pp. 794-798.

Sheskin, D.J., 2004. Handbook of Parametric and Nonparametric Statistical Procedures, The American Statistician. CRC Press, Boka Raton.

Smith, K.L., Steven, M.D., Colls, J.J., 2004. Use of hyperspectral derivative ratios in the red-edge region to identify plant stress responses to gas leaks. Remote Sensing of Environment 92, pp. 207-217.

Song, S., Gong, W., Zhu, B., Huang, X., 2011. Wavelength selection and spectral discrimination for paddy rice, with laboratory measurements of hyperspectral leaf 
reflectance. ISPRS Journal of Photogrammetry and Remote Sensing 66, pp. 672-682.

Tomlinson, P.B., 1994. The Botany of Mangroves. Cambridge University Press, Cambridge.

Tsai, F., Philpot, W., 1998. Derivative Analysis of Hyperspectral Data. Remote Sensing of Environment 66, pp. 41-51.

Vaiphasa, C., Ongsomwang, S., Vaiphasa, T., Skidmore, A.K., 2005. Tropical mangrove species discrimination using hyperspectral data: A laboratory study. Estuarine, Coastal and Shelf Science 65, pp. 371-379.

Zomer, R., Trabucco, A., Ustin, S., 2009. Building spectral libraries for wetlands land cover classification and hyperspectral remote sensing. Journal of Environmental Management 90, pp. 2170-2177. 